\title{
Effect of ADMA levels on severity of erectile dysfunction in chronic kidney disease and other risk factors
}

\author{
Kaan Gökçen, MD;1 Hakan Kılıçarslan, MD; ${ }^{2}$ Burhan Coşkun, MD,; Alparslan Ersoy, MD; Onur Kaygısız, MD;'2 \\ Yakup Kordan, $M D^{2}$
}

'Cumhuriyet University, Department of Urology, Sivas, Turkey; ${ }^{2}$ Uludag University, Department of Urology, Bursa, Turkey; ${ }^{3}$ Uludag University, Department of Nephrology, Bursa, Turkey

Cite as: Can Urol Assoc J 2016;10(1-2):E41-5. http://dx.doi.org/10.5489/cuaj.3170 Published online January 14, 2016.

\section{Abstract}

Introduction: Hormonal, neurogenic, vasculogenic, and psychogenic impairments, as well as endothelial dysfunction may play a role in erectile dysfunction (ED) in patients with chronic kidney disease (CKD). Asymmetrical dimethylarginine (ADMA) is an inhibitor of nitric oxide, which is the key element of ED. ADMA levels are increased in CKD. We aimed to evaluate the effect of serum ADMA, prolactin, testosterone, and hemoglobin levels on erectile function of patients with CKD and control subjects.

Methods: A total of 42 men with CKD and 25 age-matched controls were enrolled. The patients with CKD were categorized into group 1 and group 2 based on whether they had ED according to their response to International Index of Erectile Function questionnaire (IIEF-EFD). Group 3 was a control group. Serum ADMA, total testosterone prolactin, and hemoglobin levels of the patients were evaluated.

Results: Serum ADMA, testosterone, and hemoglobin levels were similar between group 1 and 2, serum prolactin level was significantly high in group 1 than in group 2 or 3 (control group). There was no correlation between ADMA levels and IIEF-EFD scores of patients with CKD.

Conclusions: The results of this study suggest serum ADMA level is not related with ED in patients with CKD. Also, low testosterone and hemoglobin levels were not significant factors. High levels of serum prolactin are related with ED in patients with CKD.

\section{Introduction}

Erectile dysfunction (ED) is a common condition in patients with CKD. Up to $80 \%$ of men with CKD have ED. ${ }^{1-3}$ Hormonal, neurogenic, vasculogenic, and psychogenic impairments have been reported as contributors of ED in these patients. ${ }^{1,4}$ Besides these factors, animal models of CKD suggest a role for endothelial dysfunction in ED. ${ }^{5}$
Endothelial dysfunction is a common problem in patients with CKD, hypertension, atherosclerosis, hypercholesterolemia, and diabetes mellitus. ${ }^{6}$ Nitric oxide (NO), the key element in endothelial function, ${ }^{7}$ is synthesized from L-arginine by NO synthase (NOS). ${ }^{8}$ Patients with CKD have lower serum levels of $\mathrm{L}$-arginine and $\mathrm{NO}$, as well as reduced expression of NOS isoforms in kidney and vascular tissue. ${ }^{9}$ Also, patients with CKD have elevated levels of ADMA, which is a competitive inhibitor of NOS. ${ }^{10}$ ADMA is suggested as a marker of endothelial dysfunction. ${ }^{11}$

Although ADMA is a strong predictor of impairment in endothelial function, there is lack of evidence in the literature as to whether increased levels of ADMA correlate with ED in patients with CKD. We aimed to evaluate the effect of ADMA, prolactin, testosterone, and hemoglobin levels on erectile function of patients with CKD and control subjects.

\section{Methods}

A total of 42 men with diagnosis of CKD were enrolled in this case-control study between January 2008 and August 2012. An age-matched group 25 men who were hospitalized for surgery of benign prostate hyperplasia and urinary stone disease without having CKD and ED participated as a voluntary control group. Among 42 men with CKD, 14 had Stage 3; 7 had Stage 4; and 21 had Stage 5 CKD. All of the patients with end-stage CKD had hemodialysis for renal replacement therapy. Thirteen (13) patients had renal replacement therapy for more than five years.

The status of erectile function was determined with the erectile function domain of IIEF-EFD. The degree of ED was divided into five categories: no ED (scores of 26-30), mild (scores of 22-25), mild-to-moderate (scores of 17-21), moderate (scores of 11-16), and severe (scores of 6-10). ${ }^{12}$

Groups were composed as follows: group1: patients with CKD and ED; group 2: patients with CKD without ED; group 3: control patients without CKD or ED. Exclusion criteria 
Gökçen et al.

included: age $<18$ years; presence of diabetes mellitus, dyslipidemia, stage 2 hypertension (blood pressure $>160 / 100$ $\mathrm{mmHg}$ ), constitutional heart disease, cardiac symptoms; use of beta blockers; history of pelvic surgery or radiotherapy; and acute inflammation.

For patients undergoing hemodialysis, $2 \mathrm{ml}$ of venous blood was retrieved before the dialysis session; in other subjects, fasting blood samples were retrieved at 8:00 am. Serum testosterone, prolactin, ADMA, and hemoglobin levels were evaluated. We used ADMA ELISA kit (Immundiagnostik AG, Bensheim, Germany) for determination of serum ADMA levels.

The statistical analyses were performed with IBM SPSS Statistics for Windows, (Version 20.0 Armonk, NY, USA). Data was tested with Kolmogorov-Smirnov for normal distribution. Data is given as mean \pm standard deviation (SD), with minimum and maximum values for continuous variables. The categorical data is defined as the number and percentage. One-way ANOVA and post-hoc Tukey tests were used in parametric variables. Categorical data was tested with $\mathrm{x}^{2}$ test. Correlation between variables was tested with Pearson correlation test for parametric data. Statistical significance was considered at $p \leq 0.05$.

\section{Results}

Clinical characteristics of the patients are shown in Table 1 . The mean age of the patients was 50 years $(32 \pm 9.79$; range: 29-68). There were no significant difference in ages and body mass index of groups. The number of patients with Stage 1 hypertension and the use of antihypertensive agents was significantly higher in group 1 and 2 than in group 3 .

\begin{tabular}{|c|c|c|c|c|}
\hline & Group $1(n=20)$ & Group 2 (n=22) & Group $3(n=25)$ & $p$ value \\
\hline Age (year) & $53.3 \pm 9,9$ & $48.7 \pm 10.7$ & $49.2 \pm 8.6$ & 0.212 \\
\hline BMI $\left(\mathbf{k g} / \mathrm{m}^{2}\right)$ & $25.2 \pm 4,5$ & $26.2 \pm 3.4$ & $26.7 \pm 2.5$ & 0.258 \\
\hline Hypertensive state & & & & 0.004 \\
\hline Normal & $7(35 \%)$ & $7(31.8 \%)$ & $4(16 \%)$ & \\
\hline Pre-hypertension & $5(25 \%)$ & $5(22.7 \%)$ & $18(72 \%)$ & \\
\hline Stage 1 hypertension & $8(40 \%)$ & $10(45.4 \%)$ & $3(12 \%)$ & \\
\hline Antihypertensive & & & & 0,029 \\
\hline Yes & $8(40 \%)$ & $10(45.4 \%)$ & $3(12 \%)$ & \\
\hline No & $12(60 \%)$ & $12(64.6 \%)$ & $22(88 \%)$ & \\
\hline \multicolumn{5}{|l|}{ CKD } \\
\hline Stage 3 & $6(30 \%)$ & $8(36.3 \%)$ & 0 & \\
\hline Stage 4 & $3(15 \%)$ & $4(18.2 \%)$ & 0 & \\
\hline Stage 5 & $11(55 \%)$ & $10(45.4 \%)$ & 0 & \\
\hline \multicolumn{5}{|l|}{ Erectile function status } \\
\hline No ED & 0 & $\begin{array}{c}22 \\
\text { (10: Stage } 5 \text { CKD) } \\
\text { (4: Stage } 4 \text { CKD) } \\
\text { (8: Stage } 3 \text { CKD) }\end{array}$ & 25 & \\
\hline Mild ED & 0 & 0 & 0 & \\
\hline Mild to moderate ED & $\begin{array}{c}2 \\
\text { (2: Stage } 5 \text { CKD) }\end{array}$ & 0 & 0 & \\
\hline Moderate ED & $\begin{array}{c}4 \\
\text { (3: Stage } 5 \text { CKD) } \\
\text { (1: Stage } 4 \text { CKD) }\end{array}$ & 0 & 0 & \\
\hline Severe ED & $\begin{array}{c}14 \\
\text { (6: Stage } 5 \text { CKD) } \\
\text { (2: Stage } 4 \text { CKD) } \\
\text { (6: Stage } 3 \text { CKD) }\end{array}$ & 0 & 0 & \\
\hline Hemoglobin levels & $11.9 \pm 1.8 a$ & $12.7 \pm 1.7 b$ & $13.8 \pm 1.2$ & $<0.001$ \\
\hline ADMA levels & $0.6 \pm 0.1 a$ & $0.6 \pm 0.1 b$ & $0.4 \pm 0.1$ & $<0.001$ \\
\hline Total testosterone & $2.7 \pm 1,1 a$ & $3.6 \pm 1.2 a$ & $5.7 \pm 1.9$ & $<0.001$ \\
\hline Prolactin levels & $16.9 \pm 2.2 \mathrm{a}$ & $14.6 \pm 1,7 a, c$ & $11.3 \pm 2.2$ & $<0.001$ \\
\hline
\end{tabular}


Angiotensin-converting enzyme (ACE) inhibitors were used at similar dosages in groups 1 and 2; there was no significant difference between the use of ACE inhibitors $(p=0.761)$.

The mean hemoglobin levels were significantly lower in groups 1 and 2 than in group 3. The mean ADMA levels were similar in groups 1 and 2. The mean ADMA level of group 3 was significantly lower than that of groups 1 and 2. According to a retrospective power analysis for ADMA levels of groups (Table 1), when 20 ED patients with IIEF $<26,22$ ED patients with IIEF $>25$, and 25 controls are used, post-hoc power is calculated as $0.999(\alpha=0.05)$. The mean total serum testosterone level of group 1 was significantly lower than group 3. Also, mean testosterone level of group 2 was lower than group 3 . The mean serum prolactin level in group 1 was significantly higher than group 2 and group 3 . The mean serum prolactin level in group 2 was significantly higher than group 3 (Fig. 1).
The IIEF-EFD scores of the study group were negatively correlated with age, ADMA, and prolactin levels. The IIEFEFD scores were positively correlated with testosterone and hemoglobin levels. The ADMA levels were negatively correlated with total serum testosterone and hemoglobin levels. The ADMA levels of the patients were positively correlated with prolactin levels (Table 2).

The mean age of the patients with CKD was negatively correlated with serum ADMA levels. The IIEF-EFD scores of the patients with CKD were negatively correlated with age and prolactin levels. The IIEF-EFD levels were positively correlated with testosterone levels (Table 3). There was no correlation between ADMA levels and IIEF-EFD scores of patients with CKD. Although the patients in groups 1 and 2 had similar CKD stage and duration, there was no correlation for ED with CKD status.

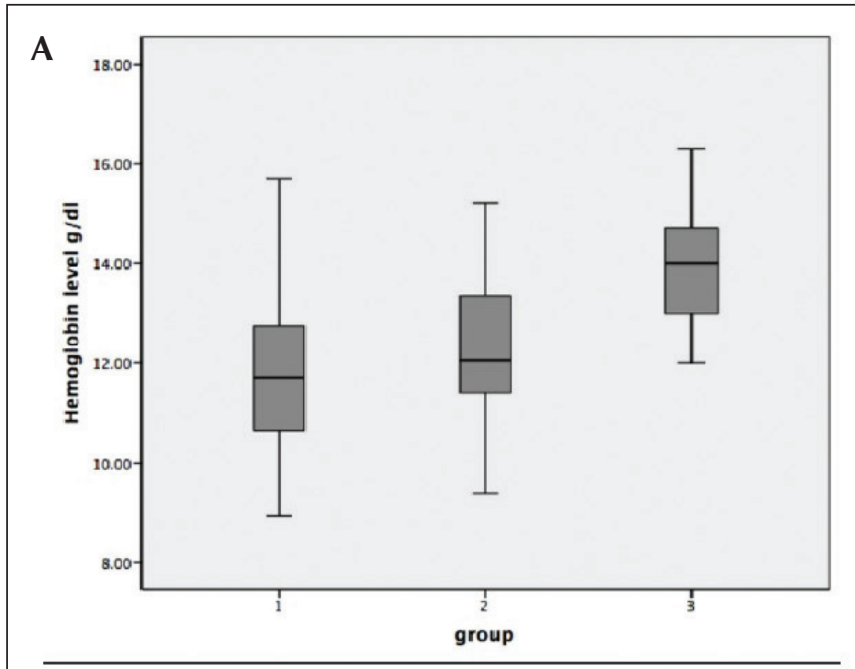

B

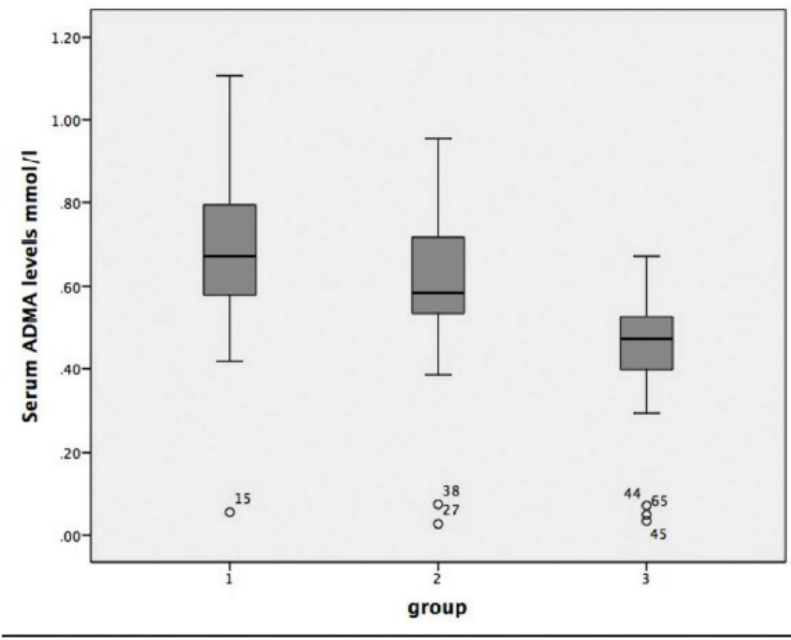

C

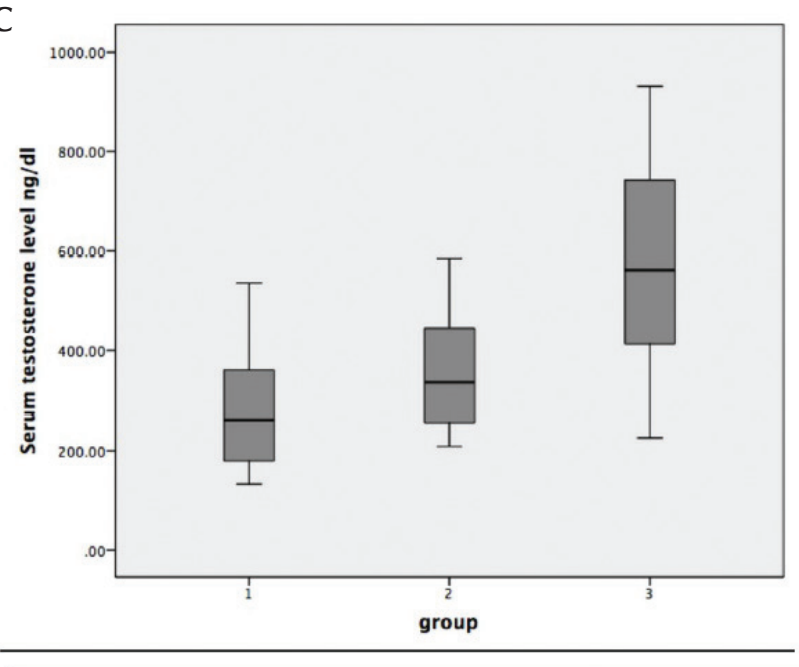

D

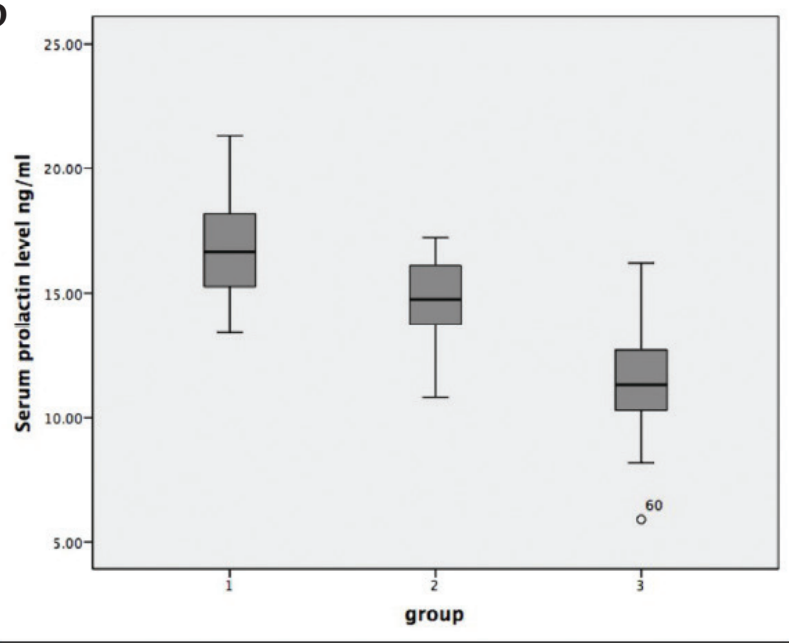

Fig. 1. Comparison of: A) hemoglobin; B) ADMA; C) testosterone; and D) prolactin levels in groups. 
Table 2. Pearson correlation for ADMA and IIEF-EFD scores of the entire patients

\begin{tabular}{lcccc}
\hline & \multicolumn{2}{c}{ ADMA } & \multicolumn{2}{c}{ IIEF-EFD score } \\
\cline { 2 - 5 } & $\mathbf{r}$ & $\boldsymbol{p}$ value & $\mathbf{r}$ & $\boldsymbol{p}$ value \\
\hline Age & -0.162 & 0.191 & -0.295 & 0.015 \\
BMI & -0.017 & 0.892 & 0.110 & 0.375 \\
Testosterone & -0.260 & 0.033 & 0.523 & $<0.0001$ \\
Prolactin & 0.361 & 0.003 & -0.642 & $<0.0001$ \\
Hemoglobin & -0.292 & 0.018 & 0.234 & 0.057 \\
IIEF-EFD score & -0.324 & 0.008 & - & -
\end{tabular}

ADMA: asymmetrical dimethylarginine; BMI: body mass index; CKD: chronic kidney disease; ED: erectile dysfunction; IIEF-EFD: erectile function domain of International Index of Erectile Function questionnaire.

\section{Discussion}

ADMA is a naturally occurring amino acid that exists as a result of proteolysis of methylated proteins. ${ }^{13}$ Type I and II protein arginine methyltransferase (PRMT) are responsible for methylation of arginine residues. ADMA is produced by the activity of PRMT type I enzyme and it plays a significant role in regulation of $\mathrm{NO}$ activity. Several factors, such as oxidative stress and increased levels of low-density lipoproteins (LDLs), are responsible for induced production of ADMA in endothelial cells. ${ }^{14}$

Besides being an endogenous inhibitor of NOS, ADMA has an additional inverse effect on the formation of $\mathrm{NO}$ by blocking the $y+$ carrier, which transports L-arginine into the cytoplasm. ${ }^{15}$ Lack of L-arginine may further decrease the amount of $\mathrm{NO}$, which is necessary for endothelial function.

ADMA levels of patients with renal failure are significantly increased in comparison to the normal population. ${ }^{13}$ The main reason for its increase in CKD is attributed to reduced activity of its metabolism rather than reduction of its clearance by urine. Also, there are increased levels of protein methylation and higher rates of protein turnover in CKD. ${ }^{16}$ ADMA is commonly metabolized by dimethylarginine dimethylaminohydrolase (DDAH), ${ }^{17}$ which exists throughout the body, but is mainly found in the kidney and liver. ${ }^{18}$

In this study, the group of patients with CKD had significantly higher serum levels of ADMA than the control patients. This finding was in accordance with other studies. ${ }^{10,13,19}$ Approximately half of patients with CKD in the present study were not having renal replacement therapy; however, the ADMA levels were not correlated with duration of CKD. Similarly, Kielstein et al reported increased levels of ADMA even in early stages of CKD. ${ }^{10}$

The discovery of the link between ADMA and CKD stimulated further research on ADMA and other pathologies that result in endothelial dysfunction, including hypertension, ${ }^{20}$ diabetes mellitus, ${ }^{21}$ obesity, smoking, ${ }^{22}$ and hypercholesterolemia. ${ }^{11}$ Moreover, ED is particularly common in these patients. ${ }^{6}$ Aktoz et al reported increased levels of ADMA in patients with coronary artery disease related with higher score of IIEF and also suggested ADMA as a marker of ED. ${ }^{23}$
Table 3: Pearson correlation for ADMA and IIEF-EFD scores of the uremic patients

\begin{tabular}{lcccc}
\hline & \multicolumn{2}{c}{ ADMA } & \multicolumn{2}{c}{ IIEF-EFD score } \\
\cline { 2 - 5 } & $\boldsymbol{r}$ & $\boldsymbol{p}$ value & $\boldsymbol{r}$ & $\boldsymbol{p}$ value \\
\hline Age & -0.353 & 0.022 & -0.341 & 0.027 \\
BMI & 0.075 & 0.636 & 0.073 & 0.644 \\
Testosterone & 0.081 & 0.609 & 0.484 & 0.001 \\
Prolactin & 0.076 & 0.632 & -0.609 & $<0.0001$ \\
Hemoglobin & -0.068 & 0.669 & 0.014 & 0.928 \\
Duration of & 0.175 & 0.268 & -0.104 & 0.513 \\
CKD & & & & - \\
IIEF-EFD score & -0.127 & 0.422 & - & - \\
\hline
\end{tabular}

ADMA: asymmetrical dimethylarginine; BMI: body mass index; CKD: chronic kidney

disease; ED: erectile dysfunction; IIEF-EFD: erectile function domain of International Index of Erectile Function questionnaire.

In a recent study, Paroni et al demonstrated a significant increase in levels of serum ADMA in patients with arteriogenic ED vs. patients with non-arteriogenic ED, which is diagnosed with Doppler ultrasonography. ${ }^{4}$ This study was designed in a healthy population. Although the clear evidence of the relation between ADMA and endothelial dysfunction has been reported in most studies; surprisingly the role of ADMA for ED in CKD population has not been demonstrated up to date.

In the present study, although there was a negative correlation between serum ADMA levels and IIEF-EFD scores of the entire patient population, there was no such correlation in patients with CKD. The main purpose of the study was to evaluate the effect of endogenous NOS inhibitors, such as as ADMA, in patients with CKD. In order to determine the net effect of ADMA on endothelial function, we did not include patients with diabetes, advanced chronic hypertension and dyslipidemia that may result in endothelial dysfunction.

The results of the present study suggest that ADMA levels are not a single factor in ED pathophysiology in patients with CKD. In an animal study, Abdel-Gewad et al demonstrated increased activity of NOS in an uremic rat model. ${ }^{24}$ This finding may explain protected erectile function in patients with CKD despite them having increased ADMA levels. W did not evaluate cavernosal endothelial ADMA levels and NOS activity. Therefore, we speculated serum ADMA levels may not correlate with local cavernosal ADMA levels.

Increased level of serum prolactin is a common finding in patients with CKD. Overproduction of this hormone is responsible for its increase. Hyperprolactinemia may cause loss of libido and low levels of serum testosterone. ${ }^{25}$ In the present study, mean prolactin levels were significantly higher in group 1 than in groups 2 and 3. Thus, hyperprolactinemia may be a contributing factor for development of ED in patients who were included in the study.

Testosterone levels of patients with CKD is usually decreased. Increased levels of serum prolactin and altered signaling of luteinizing hormone by uremia is considered 
to play a role in testosterone deficiency. ${ }^{26,27}$ Y Ilmaz et al reported lower levels of testosterone in patients with CKD, even at early stages of the disease..$^{28}$ In our group of patients with CKD, the serum levels of testosterone were significantly lower than the control group. Although mean serum testosterone levels were lower in group 1 than group 2, there was no statistical difference between both groups with CKD.

Anemia may be a contributing factor for $\mathrm{ED}^{29}$ and use of recombinant human erythropoietin may provide some benefits over sexual functions of the patients with CKD. ${ }^{30}$ In the study, group 1 had lower levels of hemoglobin than groups 2 and 3 . This finding supports the effects of hemoglobin on erectile function.

\section{Conclusion}

Serum ADMA, prolactin, testosterone, and hemoglobin levels may affect erectile function in patients with CKD. Although serum ADMA levels are increased in patients with $C K D$, the results of this study suggest serum ADMA levels are not related to ED in patients with CKD. Also, low testosterone and hemoglobin levels were not a significant factor. High levels of serum prolactin are related with ED in patients with CKD. More studies with a larger number of patients and consecutive measurement of serum ADMA levels are needed to identify this relationship.

Competing interests: The authors declare no competing financial or personal interests.

Acknowledgements: Ethics Committee Approval: Ethics committee approval was received for this study from institutional ethics committee. Informed Consent: Written informed consent was obtained from patients who participated in this study.

This paper has been peer-reviewed.

\section{References}

1. Palmer BF. Sexual dysfunction in uremia. J Am Soc Nephrol 1999;10:1381-8.

2. Abram HS, Hester LR, Sheridan WF, et al. Sexual functioning in patients with chronic renal failure. J Nerv Ment Dis 1975;160:220-6. http://dx.doi.org/10.1097/00005053-197503000-00007

3. Toorians AW, Janssen E, Laan E, et al. Chronic renal failure and sexual functioning: Clinical status versus objectively assessed sexual response. Nephrol Dial Transplant 1997;12:2654-63. http://dx.doi. org/10.1093/ndt/12.12.2654

4. Paroni R, Barassi A, Ciociola F, et al. Asymmetric dimethylarginine (ADMA), symmetric dimethylarginine (SDMA) and L-arginine in patients with arteriogenic and non-arteriogenic erectile dysfunction. Int J Androl 2012;35:660-7. http://dx.doi.org/10.1111/i.1365-2605.2012.01272.x

5. Bagcivan I, Kilicarslan $\mathrm{H}$, Sarac B, et al. The evaluation of the effects of renal failure on erectile dysfunction in a rabbit model of chronic renal failure. BJU Int 2003;91:697-701. http://dx.doi.org/10.1046/ j.1464-410X.2003.04179.x

6. Martin-Morales A, Sanchez-Cruz JJ, Saenz de Tejada I, et al. Prevalence and independent risk factors for erectile dysfunction in Spain: Results of the Epidemiologia de la Disfuncion Erectil Masculina Study. J Urol 2001;166:569-74; discussion 74-5. http://dx.doi.org/10.1016/S0022-5347(05)65986-1
7. Burnett AL. Nitric oxide in the penis: Physiology and pathology. J Urol 1997;157:320-4. http://dx.doi. org/10.1016/S0022-5347(01)65369-2

8. Moncada S, Palmer RM, Higgs EA. Nitric oxide: Physiology, pathophysiology, and pharmacology. Pharmacol $\operatorname{Rev} 1991 ; 43(2): 109-42$.

9. Vaziri ND. Effect of chronic renal failure on nitric oxide metabolism. Am J Kidney Dis 2001;38:S74-9. http://dx.doi.org/10.1053/aikd.2001.27409

10. Kielstein JT, Boger RH, Bode-Boger SM, et al. Marked increase of asymmetric dimethylarginine in patients with incipient primary chronic renal disease. J Am Soc Nephrol 2002;13:170-6.

11. Boger RH, Bode-Boger SM, Szuba A, et al. Asymmetric dimethylarginine (ADMA): A novel risk factor for endothelial dysfunction: Its role in hypercholesterolemia. Circulation 1998;98:1842-7. http://dx.doi. org/10.1161/01.CIR.98.18.1842

12. Cappelleri JC, Rosen RC, Smith MD, et al. Diagnostic evaluation of the erectile function domain of the International Index of Erectile Function. Urology 1999;54(2):346-51. http://dx.doi.org/10.1016/ S0090-4295(99)00099-0

13. Vallance $\mathrm{P}$, Leone $\mathrm{A}$, Calver $\mathrm{A}$, et al. Accumulation of an endogenous inhibitor of nitric oxide synthesis in chronic renal failure. Lancet 1992;339:572-5. http://dx.doi.org/10.1016/0140-6736(92)90865-Z

14. Boger RH, Sydow K, Borlak J, et al. LDL cholesterol upregulates synthesis of asymmetrical dimethylarginine in human endothelial cells: Involvement of S-adenosylmethionine-dependent methyltransferases. Circ Res 2000;87:99-105. http://dx.doi.org/10.1161/01.RES.87.2.99

15. Closs El, Basha FZ, Habermeier A, et al. Interference of $\mathrm{L}$-arginine analogues with L-arginine transport mediated by the y+ carrier hCAT-2B. Nitric Oxide 1997;1:65-73.

16. Jacobi J, Tsao PS. Asymmetrical dimethylarginine in renal disease: Limits of variation or variation limits? A systematic review. Am J Nephrol 2008;28:224-37. http://dx.doi.org/10.1159/000110092

17. Achan V, Broadhead $M$, Malaki $M$, et al. Asymmetric dimethylarginine causes hypertension and cardiac dysfunction in humans and is actively metabolized by dimethylarginine dimethylaminohydrolase. Arterioscler Thromb Vasc Biol 2003;23:1455-9. http://dx.doi.org/10.1161/01.ATV.0000081742.92006.59

18. Nijveldt RJ, Teerlink $T$, van Guldener $C$, et al. Handling of asymmetrical dimethylarginine and symmetrical dimethylarginine by the rat kidney under basal conditions and during endotoxaemia. Nephrol Dial Transplant 2003;18:2542-50. http://dx.doi.org/10.1093/ndt/gfg452

19. Schwedhelm E, Boger RH. The role of asymmetric and symmetric dimethylarginines in renal disease. Nat Reviews Nephrol 2011;7:275-85. http://dx.doi.org/10.1038/nrneph.2011.31

20. Surdacki A, Nowicki M, Sandmann J, et al. Reduced urinary excretion of nitric oxide metabolites and increased plasma levels of asymmetric dimethylarginine in men with essential hypertension. J Cardiovasc Pharmacol 1999;33:652-8. http://dx.doi.org/10.1097/00005344-199904000-00020

21. Abbasi F, Asagmi T, Cooke JP, et al. Plasma concentrations of asymmetric dimethylarginine are increased in patients with type 2 diabetes mellitus. Am J Cardiol 2001;88:1201-3. http://dx.doi.org/10.1016/ S0002-9149(01)02063-X

22. Eid HM, Arnesen $H$, Hierkinn EM, et al. Relationship between obesity, smoking, and the endogenous nitric oxide synthase inhibitor, asymmetric dimethylarginine. Metabolism 2004;53:1574-9. http://dx.doi. org/10.1016/j.metabol.2004.06.026

23. Aktoz T, Aktoz M, Tatli E, et al. Assessment of the relationship between asymmetric dimethylarginine and severity of erectile dysfunction and coronary artery disease. Int Urol Nephrol 2010;42:873-9. hittp:// dx.doi.org/10.1007/s11255-009-9696-9

24. Abdel-Gawad M, Huynh H, Brock GB. Experimental chronic renal failure-associated erectile dysfunction: Molecular alterations in nitric oxide synthase pathway and IGF-I system. Mol Urol 1999;3:117-25.

25. Gomez $F$, de la Cueva $R$, Wauters JP, et al. Endocrine abnormalities in patients undergoing long-term hemodialysis. The role of prolactin. Am J Med 1980;68:522-30. http://dx.doi.org/10.1016/00029343(80)90296-X

26. Schmidt A, Luger A, Horl WH. Sexual hormone abnormalities in male patients with renal failure. Nephrol Dial Transplant 2002;17:368-71. hitp://dx.doi.org/10.1093/ndt/17.3.368

27. Dunkel L, Raivio T, Laine J, et al. Circulating luteinizing hormone receptor inhibitor(s) in boys with chronic renal failure. Kidney Int 1997;51:777-84. http://dx.doi.org/10.1038/ki.1997.109

28. Yilmaz MI, Sonmez A, Qureshi AR, et al. Endogenous testosterone, endothelial dysfunction, and cardiovascular events in men with nondialysis chronic kidney disease. Clin J Amer Soc Nephrol 2011;6:1617-25. http://dx.doi.org/10.2215/CJN.10681210

29. Lawrence IG, Price DE, Howlett TA, et al. Erythropoietin and sexual dysfunction. Nephrol Dial Transplant 1997;12:741-7. http://dx.doi.org/10.1093/ndt/12.4.741

30. Kokot F, Wiecek A, Schmidt-Gayk H, et al. Function of endocrine organs in hemodialyzed patients of long-term erythropoietin therapy. Artif Organs 1995;19:428-35. http://dx.doi.org/10.1111/i.1525-1594.1995. tb02354.x

Correspondence: Dr. Kaan Gökçen, Cumhuriyet University, Department of Urology, Sivas, Turkey; kaangokcen@hotmail.com 